\title{
Design and Comparative analysis of Adsorption Refrigeration System for Refrigerants R-134a and R-410a
}

\author{
Pratik P. Kulkarni*, V. N. Kapatkar and Ameya C. Lohokare \\ †Mechanical Engineering Department, SCOE, SPPU, Pune India \\ Accepted 15 June 2016, Available online 20 June 2016, Special Issue-5 (June 2016)
}

\begin{abstract}
Adsorption refrigeration is becoming popular due to it's environmentally friendly nature and use of low GWP and $O D P$ value refrigerants. This system gives advantage of use of low temperature source such as waste heat. In present study, for better heat and mass transfer, refrigerants $R 134 a$ and $R 410 a$ are used in the system and their performance is compared. $R 134 a$ is commonly used refrigerant in automobile system. Adsorption performance is compared for temperatures at $30^{\circ} \mathrm{C}, 35^{\circ} \mathrm{C}, 40^{\circ} \mathrm{C}, 45^{\circ} \mathrm{C}$ and $50^{\circ} \mathrm{C}$. COP and SCP performance for both refrigerants is compared. Activated carbon granules (ACG) $/ R 134$ a gives highest adsorption quantity of $1.4 \mathrm{Kg} / \mathrm{kg}$ at temperature of $30{ }^{\circ} \mathrm{C}$ at $850 \mathrm{kpa}$ pressure. ACG $/ R$ 410a gives highest adsorption capacity of $1.19 \mathrm{Kg} / \mathrm{kg}$ at temperature of $30^{\circ} \mathrm{C}$. Investigation showed that $A C G / R 134$ a has promising future in the adsorption refrigeration technology due to its highest adsorption capacity.
\end{abstract}

Keywords: Adsorber Bed, Azeotropic mixture, Cycle time, Equilibrium model, Isotherms, Maxsorb III.

\section{Introduction}

In this era, there is lot of work done about theoretical and experimental aspect of the adsorption refrigeration technology. New cycles, new working pairs and new research methods has been proposed. Adsorption refrigeration technology which attracts the researchers in the world despite of problems such as poor heat and mass transfer performance causes to keep this method away from practical world. Many researchers have attempted to design some practical systems.

Hence, the effective utilization of adsorption refrigeration technology is a first step for developing an efficient air conditioning and refrigeration systems. The other step is to find an effective refrigerant which has lower environmental impact with higher adsorption capacity than the other pairs. The adsorption cooling and refrigeration system is having the advantages no free of moving parts, efficiently driven by low-temperature waste heat and do not require any synthetic lubricants.

The basic adsorption cycle contains four processes represented in Fig. 1. From A to B adsorbent in bed is heated to the pressure such that desorption of the refrigerant gets started. At stage B refrigerant starts to desorb from adsorbent. Process $B$ to $C$ takes place in the condenser which causes heat addition and it causes

*Corresponding author: Pratik P. Kulkarni desorption of vapor refrigerant that condenses in a condenser. At point $\mathrm{C}$, the adsorbent reaches its maximum temperature and it starts to decrease. Process $\mathrm{C}$ to $\mathrm{D}$ causes pressure drop in the collector. The refrigerant is then comes into evaporator with decrease in temperature of adsorbent. This leads to addition of refrigerant into evaporator. In process D-A refrigerant in the evaporator takes heat from surrounding area and hence cooling effect is obtained.

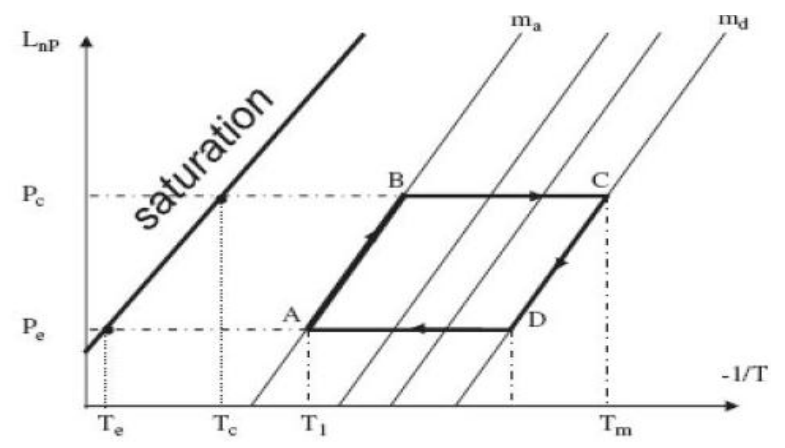

Fig. 1 Adsorption Refrigeration Cycle (Ahmed A. Askalany et al, 2013)

$\mathrm{R}-134 \mathrm{a}$ is another commonly used refrigerant in automobile air conditioning system. In new adsorption pairs R-134a gives better performance as compared to other pairs to reduce cycle time. But soon R-134a will be phase out due to high HFC content. 
R410A is a near-azeotropic mixture of difluoromethane (R32) and pentafluoroethane (R125) in equal ratio. A device was developed with minimum heat and mass transfer limitations between adsorbent and adsorbate, and practically applicable adsorption capacity data was obtained. Finned-tube heat exchanger was used. Pairs of refrigerants such as (ACP)/R-134a, ACP/R-507A, ACP/R-407c, activated carbon granules (ACG)/R-507A, ACG /R-407c and ACG /R-134a, were studied at different adsorption temperatures of ranging from 25 , 30,35 and $50^{\circ} \mathrm{C}$. At adsorption temperature of $25^{\circ} \mathrm{C}$ maximum adsorption capacity of $0.8352 \mathrm{~kg} \mathrm{~kg}-1$ for activated carbon powder with R-134a was obtained. Study showed the minimum adsorption capacity for $\mathrm{R} 407 \mathrm{c}$ with activated carbon granules as $0.1583 \mathrm{~kg} \mathrm{~kg}$ 1. Results at the temperature of $50{ }^{\circ} \mathrm{C}$ showed maximum adsorption capacity as $0.3207 \mathrm{~kg} \mathrm{~kg}-1$ for ACP with R-134a whereas the minimum adsorption capacity came as $0.0609 \mathrm{~kg} \mathrm{~kg}-1$ for activated carbon granules/R-407c. They found out as the adsorption temperature increased, the adsorption rate decreased. (Ahmed N. Shmourkh et al, 2015)

The application of adsorption pairs in cooling was studied and a classification along with a comparison for the working pairs according to its use was made. The description of adsorbate or refrigerant properties was made. The comparison of important parameters such as maximum COP, driving temperature, evaporation temperature and SCP was introduced. Comparison of traditional pairs along with new adsorption pairs was done. Many new pairs showed a promising future for cooling application. Silica gelchloride with water showed highest COP where as zeolite water pair showed lowest COP (Mahmoud salem Ahmed et $a$ ). With use of fin tube heat exchanger adsorption capacity data for various adsorbates such as ACG/R-134a, ACG/407-C, and ACG507 a for adsorption temperature of $25,30,35$, and $50^{\circ} \mathrm{C}$ was obtained. Results showed maximum capacity for ACG/R134a where as lowest of $0.1583 \mathrm{~kg} / \mathrm{kg}$ for ACG/407-C at 25 C. It also showed more adsorption capacity was found with activated carbon powder than activated carbon granules. (Ahmoud N. Shaomukh et al, 2013)

Theoretical and experimental investigation of HFC$407 \mathrm{c}$ on activated carbon was also studied in past. Experimental data was fitted with D-A and Toth equation and adsorption kinetics was studied with FD and LDF models. It was shown that D-A model with volume correlation correlates better with experimental data. Results showed maximum adsorption capacity of $0.43 \mathrm{~kg} / \mathrm{kg}$ (M.M. El-Sharkawy et al, 2015). A study was done for the adsorption kinetics of granular activated carbon/R- 134a pair with the temperature range from $20^{\circ} \mathrm{C}$ to $60^{\circ} \mathrm{C}$ and at 10 bar of pressure. The DubininAstakhov adsorption equilibrium model was found fitted to experimental data with acceptable error limit. It was designed for the bed and built it with finned tubes heat exchanger to increase the heat transfer area. It was found that the adsorption capacity/kg of adsorbent increases rapidly when relative pressure at the beginning of the adsorption process is increased The maximum adsorption capacity was founded as $1.92 \mathrm{~kg} / \mathrm{kg}$ at $20^{\circ} \mathrm{C}$ after $1200 \mathrm{~s}$ cycle time. The maximum adsorption capacity decreases to $1.31 \mathrm{~kg} / \mathrm{kg}$ with the increase in adsorbent temperature at $60^{\circ} \mathrm{C}(\mathrm{M}$. Attalla et al, 2014). A study was made for adsorption isotherms of R-134a (HFC-134a) on Maxsorb III activated carbon in the temperature range of $5-70{ }^{\circ} \mathrm{C}$ and pressures upto 12 bar, using desorption method. Correlation of data for Dubinin-Astakhov (D-A) equation was studied and compared with the results performed by other researchers. Heat of adsorption was obtained in the range from 22,000 to $28,000 \mathrm{~J} / \mathrm{mol}$. (Bidyut Saha et al, 2009). Comparison of equilibrium of activated carbon was studied with refrigerants such as R134a, R410a and 507a at temperature range of $278 \mathrm{~K}$ to $338 \mathrm{~K}$ and pressure of $1.4 \mathrm{MPa}$. Results showed the limiting uptake $\left(\mathrm{q}_{\mathrm{o}}\right)$ increases with density of refrigerants. (Wai Soong Loh et al, 2012).

\section{Experimental Setup}

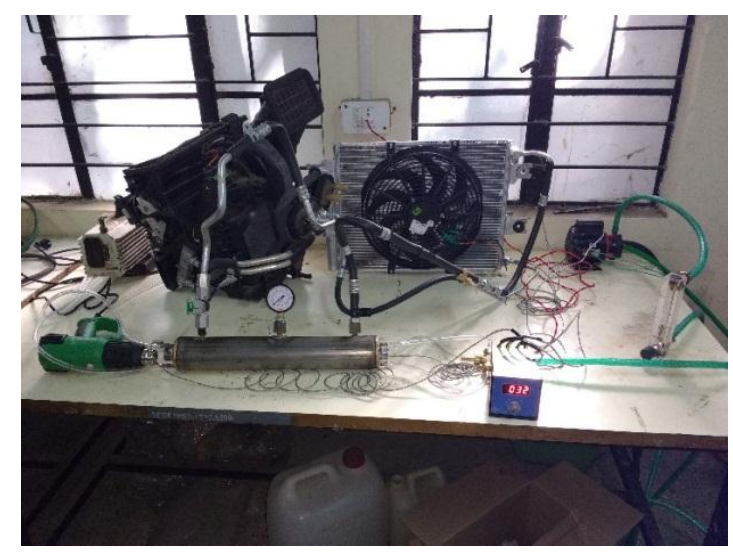

Fig.2 Experimental Setup

Experimental setup consists of one adsorber bed with pressure gauges of 30 bar rating connected to it. The hot air is supplied to the bed with help of hot air gun as shown in the figure 3. Gun has variable flow capacity from $0.25 \mathrm{~m}^{3} / \mathrm{min}$ to $0.5 \mathrm{~m}^{3} / \mathrm{min}$ and temperature variation from $50^{\circ} \mathrm{C}$ to $610^{\circ} \mathrm{C}$.

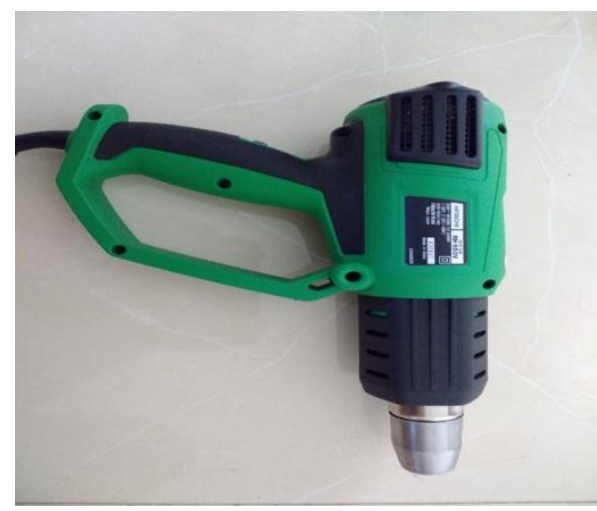

Fig.3 Hot air Supply Unit 
Condenser with the capacity of $9 \mathrm{~kW}$ is used to cool the refrigerant. Thermal Expansion valve of 1 Ton capacity is connected in the system. Evaporator of $4 \mathrm{~kW}$ capacity is used. Two solenoid valves for a bed are used to control the flow of refrigerants. 12V DC Supply is used to run condenser fan and solenoid valves. Adsorber bed is made of Stainless steel material. J Type thermocouples are used to measure the temperature at the various points in the system. Two digital display with 8 switches each are used to note down the temperature readings.

A rotameter is used to control the flow of cooling water. A $0.3 \mathrm{hp} \mathrm{AC} \mathrm{pump} \mathrm{is} \mathrm{used} \mathrm{to} \mathrm{circulate} \mathrm{cooling}$ water through adsorber bed. Two refrigerants R-134a and R-410a are used each at a time in the system. A vacuum pump is used to create negative pressure in the system and then refrigerant is filled.

Table 1 Component Specification

\begin{tabular}{|c|c|}
\hline Component & Description \\
\hline Condenser & $\begin{array}{c}9 \mathrm{~kW}, \\
\text { Size: } 390 \mathrm{~mm} \times 290 \mathrm{~mm} \times 16 \mathrm{~mm}\end{array}$ \\
\hline Evaporator & $\begin{array}{c}4 \mathrm{~kW} \\
\text { Size: } 240 \mathrm{~mm} \times 240 \mathrm{~mm} \times 58 \mathrm{~mm}\end{array}$ \\
\hline $\begin{array}{c}\text { Thermal } \\
\text { Expansion Valve }\end{array}$ & Capacity - 1 TR \\
\hline Pipes & $\begin{array}{cc}\text { Liquid Pipes } & : \Phi 8 \mathrm{~mm} \\
\text { Suction Pipes } & : \Phi 16 \mathrm{~mm} \\
\text { Discharge Pipes : } \Phi 12 \mathrm{~mm} \\
\text { Material used } \quad: \text { Stainless steel. }\end{array}$ \\
\hline Refrigerants & $\begin{array}{l}\text { R-410a } \\
\text { R-134a }\end{array}$ \\
\hline Adsorbent & $\begin{array}{l}\text { Activated Carbon Granules } \\
\text { ( Charcoal) }\end{array}$ \\
\hline Hot Fluid Supply & Temperature 100 to $200^{\circ} \mathrm{C}$ \\
\hline Radiator & Water at ambient temperature $30^{\circ} \mathrm{C}$ \\
\hline
\end{tabular}

\section{Mathematical Model}

For adsorption refrigeration system each parameter such as adsorber capacity, adsorption rate, total power input, evaporative effect, COP, SCP are mathematically modelled as follows:

\subsection{Adsorber}

The Dubinin-Astakhov (D-A) equation relates the concentration and temperature is represented as

$$
x=x_{0} \exp \left[-K\left(\frac{T}{T_{S}}-1\right)^{n}\right]
$$

$\mathrm{X}$ is the concentration of refrigerant adsorbed in bed at the temperature of the adsorption, T. Ts is the saturated temperature in the adsorber at given pressure, P. The saturated adsorption capacity of the working pair is given by $x o$. The parameter $k$ and $n$ are constants which varies with different working pair.

\subsection{Adsorption Rate}

System is divided into two phase adsorption and desorption. Cycle time will depend upon the adsorption and desorption rate.
Adsorption:

$\frac{d x_{a d s}}{d t}=\mathrm{K}_{\mathrm{ads}}\left(\mathrm{X}_{\mathrm{ads}, \mathrm{eq}}-\mathrm{X}_{\mathrm{ads}}\right)$

Desorption:

$\frac{d x_{d e s}}{d t}=\mathrm{K}_{\mathrm{des}}\left(\mathrm{X}_{\mathrm{des}}\right)$

\subsection{Total Heat Input}

$\mathrm{P}=m_{h} \dot{c}_{p h}\left(T_{\text {in }}-T_{\text {out }}\right)$

\subsection{Condenser and Evaporator Heat Balance}

Condenser Balance:

$\dot{m}_{r e f} C_{p, r e f}\left(T_{d e s}-T_{c o n d}\right)+h_{v, r e f}=\dot{m}_{a i r} C_{p, a i r}\left(T_{o u t}-\right.$

$\left.T_{\text {in }}\right)$

Evaporator Balance:

$$
\begin{gathered}
h_{v, r e f}-\dot{m}_{\text {ref }} C_{p, r e f}\left(T_{\text {cond }}-T_{\text {eva }}\right)= \\
\dot{m}_{\text {air }} C_{p, a i r}\left(T_{\text {in }}-T_{\text {out }}\right)
\end{gathered}
$$

\subsection{COP and SCP}

Adsorption refrigeration system evaluation is done with the parameters such as Coefficient of performance (COP) and Specific cooling power (SCP)

$\mathrm{COP}=\frac{Q_{\text {eva }}}{Q_{\text {in }}}$

$\mathrm{SCP}=\frac{Q_{e v a}}{m_{\dot{a} d s}}$

\section{Result and discussion}

Adsorption refrigeration system is implemented for refrigerants R134a and R410a. Adsorption quantity of refrigerants is measured for different pressures starting from 0.5 bar upto 8.5 bar at $30^{\circ} \mathrm{C}$ bed temperature.

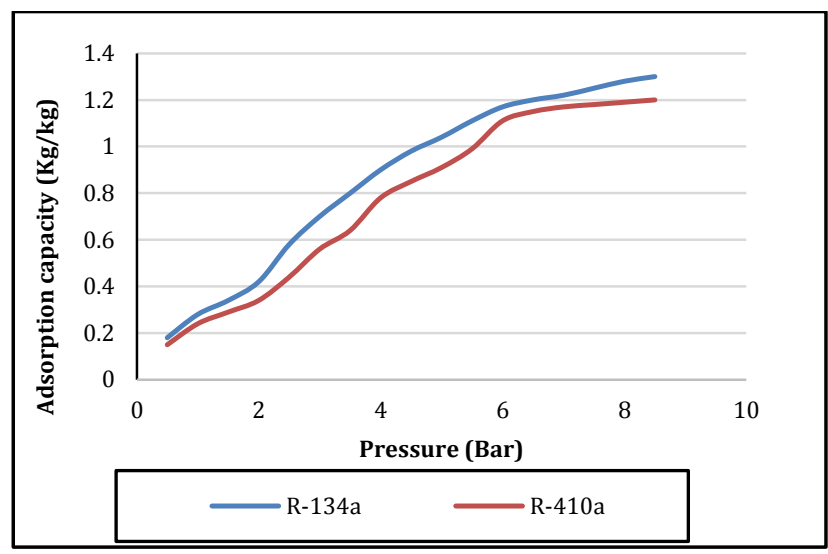

Fig 4. Adsorption capacity for various pressure at constant bed temperature of $30^{\circ} \mathrm{C}$ 
Test results showed that R-134a gives highest value of adsorption capacity $1.4 \mathrm{Kg} / \mathrm{kg}$ at 8.5 bar whereas $\mathrm{R}$ 410a gives capacity of $1.2 \mathrm{Kg} / \mathrm{kg}$ for same pressure. Adsorption capacity at $45^{\circ} \mathrm{C}$ for R-134a shows capacity of $1.22 \mathrm{Kg} / \mathrm{kg}$ and $\mathrm{R}-410 \mathrm{a}$ shows $1.18 \mathrm{Kg} / \mathrm{kg}$.

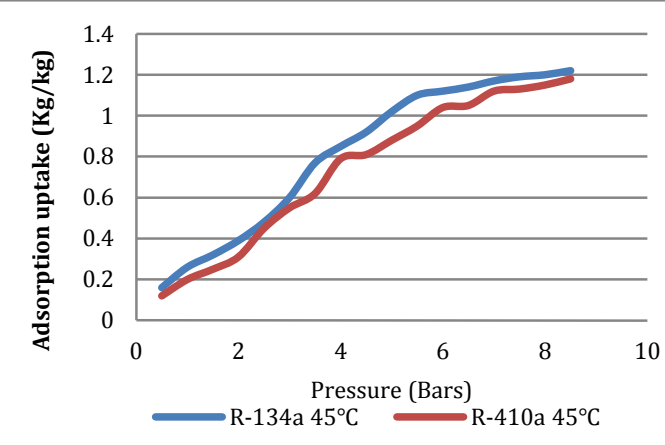

Fig 5. Adsorption capacity for various pressure at constant bed temperature of $45^{\circ} \mathrm{C}$.

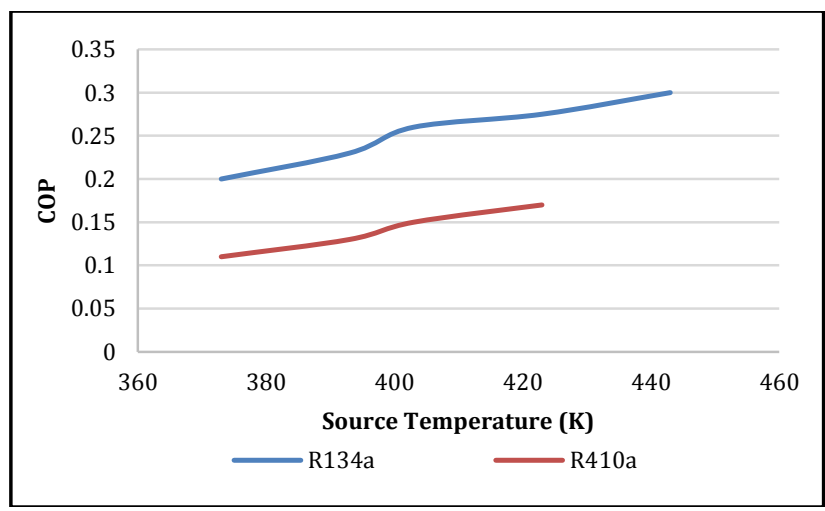

Fig 6 COP values for different source temperature

Fig. 6 shows the Coefficient of performance (COP) values at various source temperature for R134a and R410a. Figure shows that increasing source temperature increases the refrigerating effect at constant evaporator temperature. Due to lower critical point, R410a don't show COP values after 423K.

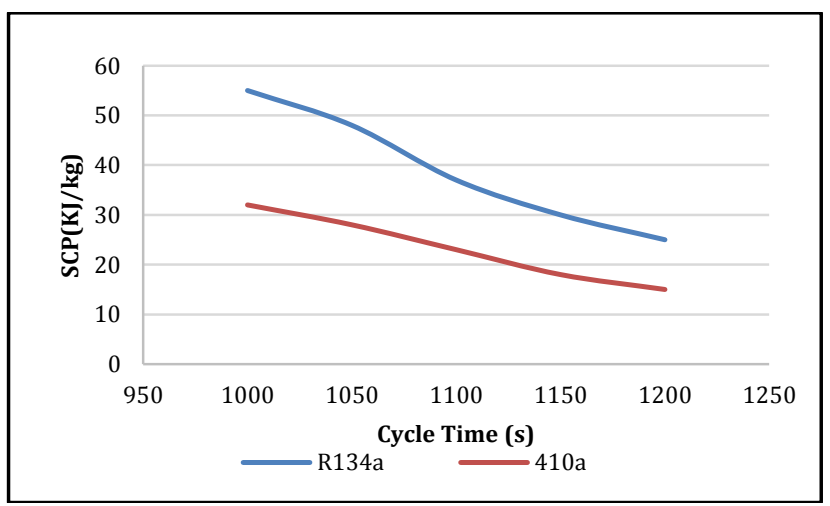

Fig 7 Specific cooling power of system at varying cycle time

Specific cooling power for both refrigerants decreases with rise in cycle time at constant source temperature.
Due to lower mass adsorbed in bed R134a, at start, shows sudden rise in SCP. In case of R410a system mass adsorbed in decreasing slowly due to its low adsorption kinetics. Hence R410a shows nearly horizontal nature for increasing cycle time. Highest SCP shown by R134a at cycle time of 1000 s is $55 \mathrm{KJ} / \mathrm{kg}$.

\section{Conclusion}

When adsorption refrigeration system with single bed is provided with two refrigerants $\mathrm{R} 134 \mathrm{a}$ and $\mathrm{R} 410 \mathrm{a}$ separately following conclusions are obtained:

1) With proper Adsorbent/refrigerant pair, performance of adsorption refrigeration system can be enhanced.

2) When bed temperature is increased the adsorption capacity goes on decreasing.

3) $\mathrm{R} 134 \mathrm{a}$ shows highest adsorption capacity of $1.4 \mathrm{Kg} / \mathrm{kg}$ at the bed temperature of $30^{\circ} \mathrm{C}$. R410a shows capacity of $1.2 \mathrm{Kg} / \mathrm{kg}$ for the same temperature.

4) COP and SCP values are higher in case of R134a as compared to R410a.

5) R410a shows poor performance at higher source temperature.

6) From comparison results showed that R134a is having high scope in adsorption refrigeration technology among new refrigerants.

\section{References}

Ahmed A. Askalany, M. Salem, I.M. Ismael, A.H.H. Ali, M.G. Morsy, Bidyut B. Saha (2013), An overvie on adsorption pairs for cooling, Renewable and sustainable energy reviews 19, pp. 565-572.

Ahmed N. Shmroukh, Ahmed Hamza H. Ali, Ali K. Abel-Rahman and S. Ookwara (2015), Experimental Investigation on adsorption capacity of a variety of activated carbon/Refrigerant Pairs, International journal of Engineering Research and applicattions, pp. 66-76.

Mahmoud salem ahmed, ahmed abd el kadar shehata, A review: Future of the adsorption working pairs in cooling,pp. 1-16

Ahmed N. Shmroukh, Ahmed Hamze H., Ali K. AbelRahman(2013), Experimental study on adsorption capacity of activated carbon pairs with different refrigerants, International journal of Chemical, Molecular, Nuclear, Materials and metallurgical engineering, pp. 461-467.

M. Attalla, S. Sadek(2014), Experimental Investigation of Granular Activated Carbon/R134a pair for adsorption cooling system applications, Journal of power and energy engineering, pp. 11-20.

Bidyut B. Saha, Khairul Habib, Ibrahim I. El-Sharkawy, Shigeru koyama(2009), Adsorption characteristics and heat of adsorption measurements of $\mathrm{R} 134 \mathrm{a}$ on activated carbon, International journal of refrigeration 32, pp. 1563-1569.

Wai soong loh, Azhar Bin Ismail, Baijuan Xi, Kim choon Ng and won gee chun(2012), Adsorption isotherms and isosteric enthalpy of adsorption for assorted refrigerants on activated carbons, journal of chemical and engineering data, pp. 27662773.

H. R. Ramji, S. L. Leo, I. A. W. Tan and M. O. Abdullah (2014), Comparative study of three different adsorbent-adsorbate working pairs for a waste heat driven adsorption air conditioning system based on simulation, IJRRAS 18 (2), pp. 109-121.

Ahmed A. Askalany, Bidyut B. saha, Mahmoud S. Ahmed, Ibrahim M. Ismail (2013), Adsorption cooling system employing granular activated carbon-R134a pair for renewable energy applications, International journal of refrigeration 36 , pp 1037-1044 